\title{
Finite element analysis of compression fractures at the thoracolumbar junction using models constructed from medical images
}

\author{
DAISUKE NAKASHIMA ${ }^{1}$, TSUKASA KANCHIKU ${ }^{1}$, NORIHIRO NISHIDA ${ }^{1}$, SAKI ITO ${ }^{2}$, JUNJI OHGI ${ }^{2}$, \\ HIDENORI SUZUKI $^{1}$, YASUAKI IMAJO ${ }^{1}$, MASAHIRO FUNABA ${ }^{1}$, XIAN CHEN $^{2}$ and TOSHIHIKO TAGUCHI ${ }^{1}$ \\ ${ }^{1}$ Department of Orthopedic Surgery, Yamaguchi University Graduate School of Medicine, Ube, Yamaguchi 755-8505; \\ ${ }^{2}$ Department of Mechanical Engineering, Yamaguchi University, Ube, Yamaguchi 755-8611, Japan
}

Received September 28, 2017; Accepted November 9, 2017

DOI: $10.3892 / \mathrm{etm} .2018 .5848$

\begin{abstract}
Vertebral fractures commonly occur at the thoracolumbar junction. These fractures can be treated with mild residual deformity in many cases, but are reportedly associated with increased risk of secondary vertebral fractures. In the present study, a three-dimensional (3D) whole spine model was constructed using the finite element method to explore the mechanism of development of compression fractures. The 3D model of the whole spine, from the cervical spine to the pelvis, was constructed from computed tomography (CT) images of an adult male. Using a normal spine model and spine models with compression fractures at the T11, T12 or L1 vertebrae, the distribution of strain was analyzed in the vertebrae after load application. The normal spine model demonstrated greater strain around the thoracolumbar junction and the middle thoracic spine, while the compression fracture models indicated focused strain at the fracture site and adjacent vertebrae. Increased load time resulted in the extension of the strain region up to the middle thoracic spine. The present findings, that secondary vertebral fractures commonly occur around the fracture site, and may also affect the thoracic vertebrae, are consistent with previous clinical and experimental results. These results suggest that follow-up examinations of compression fractures at the thoracolumbar junction should include the thoracic spine and adjacent vertebrae. The current data also demonstrate that models created from CT images can be used for various analyses.
\end{abstract}

Correspondence to: Dr Norihiro Nishida, Department of Orthopedic Surgery, Yamaguchi University Graduate School of Medicine, 1-1-1 Minami-Kogushi, Ube, Yamaguchi 755-8505, Japan E-mail: nishida3@yamaguchi-u.ac.jp

Key words: finite element method, spinal compression fracture, thoracolumbar junction, secondary vertebral fracture, computed tomography

\section{Introduction}

With the aging of the population, there is an ongoing increase in the number of patients with osteoporosis (1). Reportedly, $>50 \%$ of women in their 80 s are osteoporotic (2), while $40 \%$ have vertebral compression fractures (3). Vertebral fractures commonly occur at the thoracolumbar junction. These fractures can be treated with mild residual deformity in many cases, but are reportedly associated with increased risk of secondary vertebral fractures (4-6). In patients with osteoporosis-associated vertebral fractures, the risk of secondary vertebral fractures appears to increase with each additional fracture (2). Compared with patients without vertebral fractures, patients with one vertebral fracture and those with multiple vertebral fractures are reported to have a 3.2- and 6.7-fold higher risk of experiencing secondary vertebral fractures, respectively (7).

Various therapies and clinical/experimental studies have been reported for vertebral compression fractures (8-12). For the prevention of osteoporotic vertebral fractures, it is reported that bisphosphonates, including etidronate, alendronate, minodronic acid, risedronate, ibandronate suppress the onset of vertebral fractures by 36-62\% (13-17), teriparatide suppresses onset of vertebral fracture by $65-80 \%$ (18-19) and denosumab suppressed onset of vertebral fracture by $68 \%$ (20). Regarding the treatment of osteoporotic vertebral fractures, alignment can be corrected by performing vertebroplasty or spinal shortening osteotomy, but in the case of conservative treatment, there is a possibility that kyphotic deformity will remain $(21,22)$. Regarding alignment abnormalities following osteoporotic vertebral fractures, it is possible to evaluate the mechanism of secondary vertebral fractures by creating a fracture model using the finite element method and performing mechanical analysis, however to the best of our knowledge, this is the first study to create a three-dimensional whole spine model directly from a medical image and perform a mechanical analysis. The authors propose that it is important to extract a model from each patient's medical images and to perform individualized analysis in future clinical practice. The aim of the present study was to construct a normal whole spine model and compression fracture models with vertebral deformities at T11, T12 and L1 vertebrae, which are commonly 
affected by compression fractures, from the medical images of a patient using FEM. Furthermore, the validity of the models and the mechanism of development of secondary compression fractures were determined.

\section{Materials and methods}

Patient images. Computed tomography (CT) images (0.67-mm slice thickness) of the whole spine, ranging from the cervical spine to the pelvis, of an adult male (Japanese, aged 32 years) were obtained with the Brilliance 64 CT scanner (Philips Healthcare, Amsterdam, The Netherlands). The use of these CT images was approved by the ethics committee at the Center for Clinical Research, Yamaguchi University Hospital (Ube, Japan; approval no. H29-052).

Model construction. Model construction was performed with FEM analysis software, Simpleware ScanIP version M-2017.06 (Synopsys, Inc. Mountain View, CA, USA. After the spine was extracted, vertebrae were mapped into cancellous and cortical bones and the sizes of intervertebral discs (IVDs) were adjusted to match the sizes of end plates of each vertebra (Fig. 1). A 3D whole spine model was constructed by individually mapping all vertebrae and IVDs from the cervical to sacral regions. The gap between each vertebra and IVD was regarded as completely restricted in movement. Facet joint spaces were created at all levels so that each vertebra could move independently. The model without compression fracture was defined as the normal spine model. Whole spine models with compression fractures were created by trimming the cranial and caudal surfaces of the T11, T12 or L1 vertebrae by $5^{\circ}$ and $10^{\circ}$ to make the angle formed by the cranial and caudal surfaces of each vertebra $10^{\circ}$ and $20^{\circ}$, respectively, and also by rotating IVDs on the cranial and caudal sides of each vertebra (Fig. 2). These were defined as T11 $10^{\circ}$, T11 $20^{\circ}$, T12 $10^{\circ}, \mathrm{T} 1220^{\circ}, \mathrm{L} 110^{\circ}$ and L1 $20^{\circ}$ compression fracture models. Considering that in normal sagittal alignment, a perpendicular line from the center of the $\mathrm{C} 7$ vertebra passes through the center of the upper surface of the sacral vertebrae (23), the standing position was reproduced by rotating the sacral vertebrae to compensate for kyphosis.

In the normal model, the total number of elements and nodes was 405,335 and 1,875,549, respectively. In this analysis, all elements were considered to be linear elastic materials. Young's modulus was set as cortical bone: 12,000 $\mathrm{MPa}$, cancellous bone: 1,500 MPa, IVD: $10 \mathrm{MPa}$. Poisson's ratio was set as cortical bone: 0.3 , cancellous bone: 0.3 , IVD: 0.4 , according to a previously published paper (24). Dynamic analysis was performed assuming that the volunteer fell on his/her buttocks and load was applied to the spine.

Load application. Assuming that the pelvis was in a consistent position during the fall and the sacroiliac joint was fixed, a 1,200-N load, corresponding to two-thirds of the body weight $(60 \mathrm{~kg})$ excluding the feet, was applied in a vertical direction, distributed according to the number of nodes of the whole spine. The load rise time was set at $0.002 \mathrm{sec}$. Analysis was performed using Jvision version 3.3.0 (JSOL Corporation, Tokyo, Japan) and LS-DYNA version R9.1.0 (JSOL Corporation) software.

\section{Results}

Fig. 3 indicates the distribution of the minimum principal strain of the spinal model after $0.004 \mathrm{sec}$ and Fig. 4 indicates the distribution of the minimum principal strain of the spinal model after $0.01 \mathrm{sec}$. Fig. 5 presents graphs of the minimum principal strain after $0.004 \mathrm{sec}$ and Fig. 6 presents graphs of the minimum principal strain after $0.01 \mathrm{sec}$.

At $0.004 \mathrm{sec}$ after load application, peak strain was observed not only at the thoracolumbar junction, but also in the middle thoracic spine in the normal spine and compression fracture models (T11 $10^{\circ}, \mathrm{T} 1120^{\circ}, \mathrm{T} 1210^{\circ}, \mathrm{T} 1220^{\circ}$ and $\mathrm{L} 11^{\circ}$; Figs. 3 and 5)

At $0.01 \mathrm{sec}$ after load application, peak strain shifted to the thoracic spine in the normal spine model. In the compression fracture models, peak strain moved to the thoracic vertebrae, but the larger the fracture angle, the less the movement to the thoracic vertebrae. (T $1120^{\circ}$, T $1220^{\circ} \mathrm{L} 120^{\circ}>\mathrm{T} 1110^{\circ}$, T 12 $10^{\circ}$, L $110^{\circ}>$ normal; Figs. 4 and 6).

\section{Discussion}

Spinal compression fractures commonly occur at the thoracolumbar junction (T11 to L2 level), which is biomechanically vulnerable to stress and can lead to kyphotic deformity of the spine at the fracture site (25). Lumbar kyphosis is compensated for by reduced thoracic kyphosis to maintain the sagittal balance, while thoracic kyphosis is compensated for by increased lordosis of the lumbar spine (26). This results in altered alignment of the whole spine and altered load application to each vertebra, which is a suggested cause of secondary compression fracture.

Regarding reduced quality of life (QOL) due to compression fracture, Glassman et al $(27,28)$ have reported that increased anterior inclination of the body trunk is associated with greater impairment of QOL. Miyakoshi et al (29) have reported reduced QOL due to poor sagittal balance, where kyphosis of the thoracic or lumbar spine is associated with marked reduction in QOL. Takahashi et al (30) reported that worsening of gait disturbance due to spinal kyphosis is associated with reduced frequency of going outdoors, leading to reduced satisfaction with daily life. These reports suggest the importance of preventing secondary compression fractures. For the prevention of secondary compression fractures, the importance of osteoporosis treatment has been emphasized and various surgical therapies, including balloon kyphoplasty, have been proposed (13-17,31).

While the usefulness of FEM analysis of the spine has been demonstrated in many studies (8-12), only a few studies have analyzed spinal compression fracture by FEM. Imai et al (32) compared the results of FEM analysis and an actual compression experiment using samples of the thoracolumbar junction collected from fresh cadavers and demonstrated that bone strength and fracture sites can be predicted by FEM analysis. Tawara et al (33-35) reported the usefulness of FEM analysis for examining osteoporotic spines using CT images of bisphosphonate-treated patients, although they only analyzed limited intervertebral spaces and did not take into account the anatomical variability across the whole spine. 


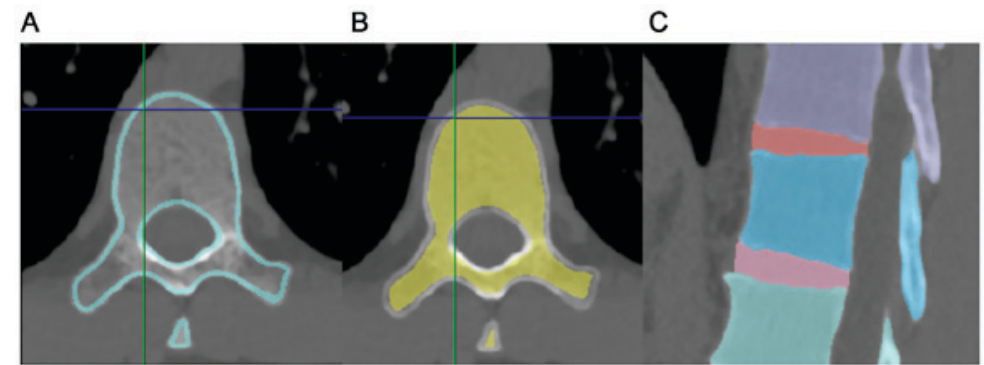

Figure 1. Normal model construction. (A) Cortical bone, (B) cancellous bone and (C) intervertebral discs were mapped from computed tomography images.

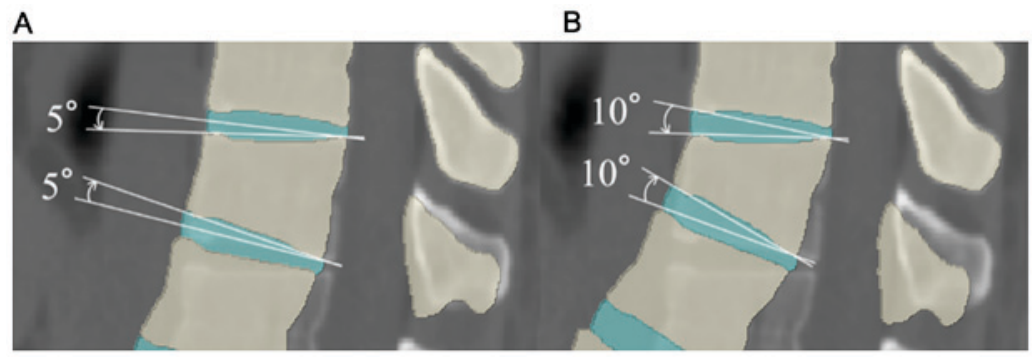

Figure 2. Compression model construction. (A) The T11 $10^{\circ}$ compression fracture model was created by trimming the cranial and caudal surfaces of the T11 vertebrae by $5^{\circ}$ each. (B) The T11 $20^{\circ}$ compression fracture model was created by trimming the cranial and caudal surfaces of the T11 vertebrae by $10^{\circ}$ each.

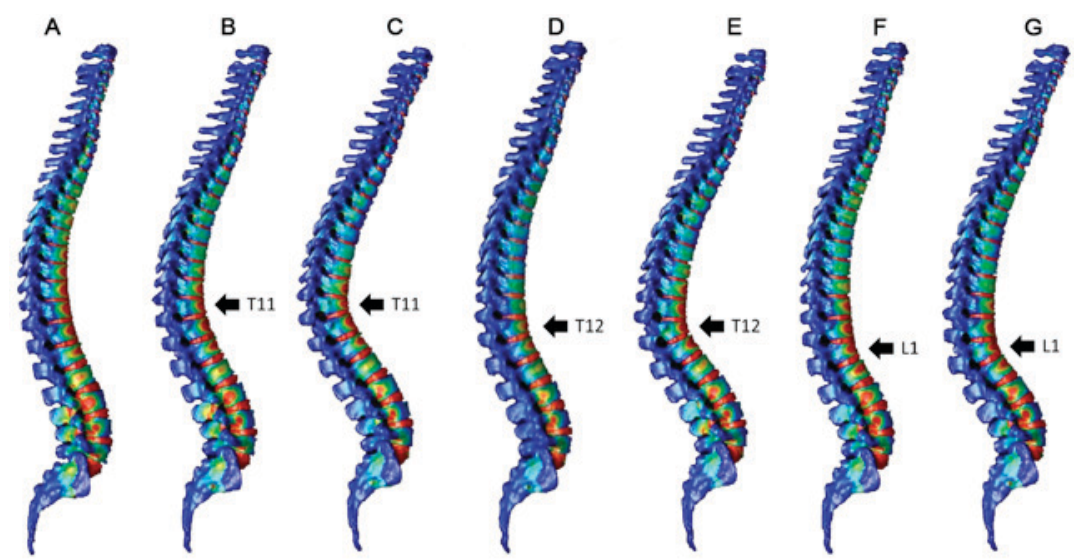

Figure 3. Computer model of load application after $0.004 \mathrm{sec}$. (A) Normal spine model. (B) T11 $10^{\circ}$ compression fracture model. (C) T11 $20^{\circ}$ compression fracture model. (D) T12 $10^{\circ}$ compression fracture model. (E) T12 $20^{\circ}$ compression fracture model. (F) L1 $10^{\circ}$ compression fracture model. (G) L1 $20^{\circ}$ compression fracture model.
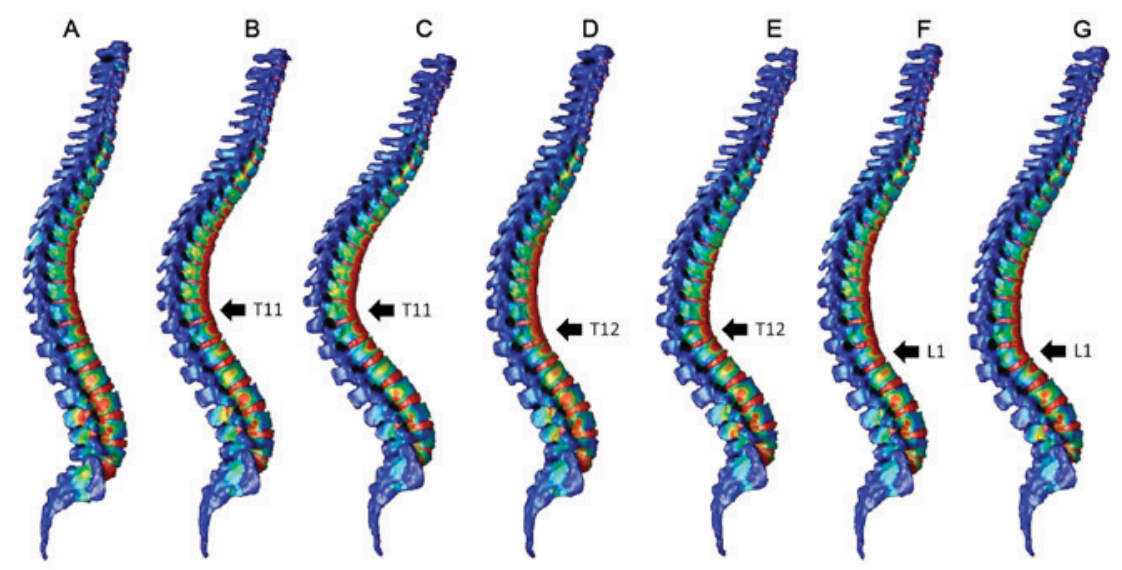

Figure 4. Computer model of load application after $0.01 \mathrm{sec}$. (A) Normal spine model. (B) T11 $10^{\circ}$ compression fracture model. (C) T11 $20^{\circ}$ compression fracture model. (D) T12 $10^{\circ}$ compression fracture model. (E) T12 $20^{\circ}$ compression fracture model. (F) L1 $10^{\circ}$ compression fracture model. (G) L1 $20^{\circ}$ compression fracture model. 

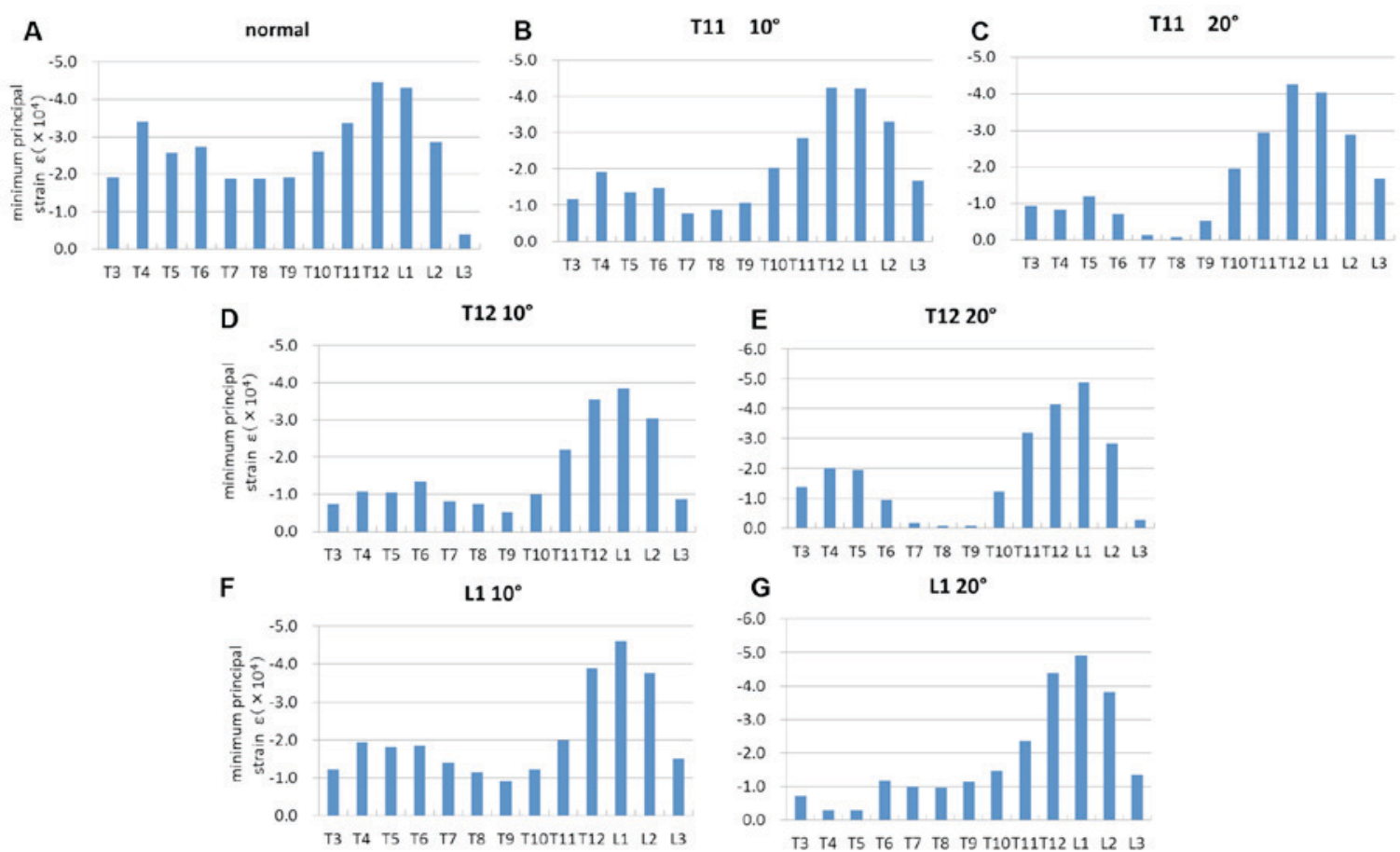

Figure 5. Minimum principal strain after $0.004 \mathrm{sec}$. (A) Normal spine model. (B) T11 $10^{\circ}$ compression fracture model. (C) T11 $20^{\circ}$ compression fracture model. (D) T12 $10^{\circ}$ compression fracture model. (E) T12 $20^{\circ}$ compression fracture model. (F) L1 $10^{\circ}$ compression fracture model. (G) L1 $20^{\circ}$ compression fracture model.
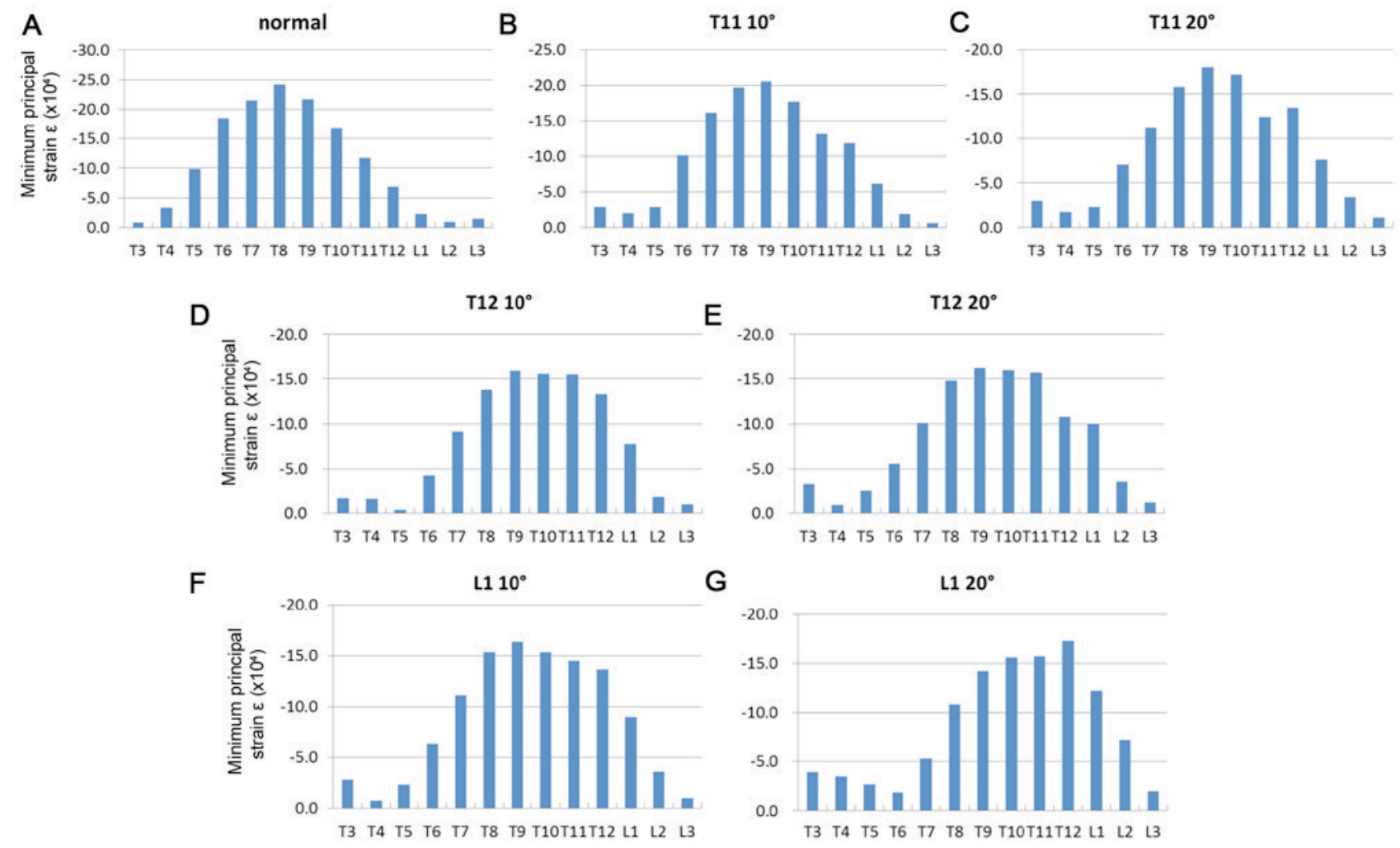

Figure 6. Minimum principal strain after $0.01 \mathrm{sec}$. (A) Normal spine model. (B) T11 $10^{\circ}$ compression fracture model. (C) T11 $20^{\circ}$ compression fracture model. (D) T12 $10^{\circ}$ compression fracture model. (E) T12 $20^{\circ}$ compression fracture model. (F) L1 $10^{\circ}$ compression fracture model. (G) L1 $20^{\circ}$ compression fracture model.

Although used in a limited number of reports as described above, FEM analysis has been demonstrated to be effective for the clinical analysis of compression fractures and other conditions. Based on the proposal that FEM analysis of compression fractures using whole spine models extracted from medical images of patients could be effective for the 
prevention of secondary compression fractures, models were created in the current study. It was investigated whether the obtained findings were consistent with those reported in clinical and experimental studies.

Osteoporotic spinal compression fractures have been reported to occur most commonly at the thoracolumbar junction (4-6). The current results also demonstrated focused strain at the thoracolumbar junction in the normal spine model, which was consistent with previous findings. Secondary compression fractures have been reported to occur most commonly in adjacent vertebrae, followed by the middle thoracic spine (36). The compression fracture models of the present study revealed focused strain in the fractured vertebra and adjacent vertebrae within a short time, more prominently as compared with the normal spine model, and spread of strain up to the middle thoracic spine over time, which was consistent with previous clinical findings.

The present study had certain limitations. First, the present models did not consider ligaments, particularly the supraspinatus and interspinatus ligaments, joint capsule, muscles and ribs. Second, anterior inclination associated with spinal compression fracture was compensated for only by rotation of the pelvis in our models; however, in actual patients, it is compensated for by inclination, in addition to rotation, of the pelvis and the IVD-lower limb alignment $(26,37)$. Other limitations include the assumption that the material constants of vertebrae and IVDs and bone mineral density were fixed, and that consistent load was applied to the spine when the patient fell on his/her buttocks. Finally, the analysis did not consider the patient's posture, the hardness of the ground or the time elapsed during the fall.

Nevertheless, the findings obtained from the whole spine model and compression fracture models created from medical images in the present study support previous findings. The development of improved models that overcome the aforementioned limitations may contribute to the prevention of damage to adjacent IVDs and progression to burst fractures, and also to the development of rehabilitation programs to compensate for stress applied to the fractured vertebrae.

In conclusion, FEM models were created of the whole spine from medical images and strain analysis was performed using compression fracture models. The normal spine model exhibited a shift of high strain region from the thoracolumbar junction to the middle thoracic spine, while the compression fracture models exhibited focused strain at the fracture site and adjacent vertebrae. These results supported the previous findings, and suggested that whole spine models created from medical images could be used for various types of analysis.

\section{Acknowledgements}

The authors would like to thank the members of the Medical and Mechanical Engineering Laboratory of Yamaguchi University, and graduate students from this laboratory, for their assistance with this study.

\section{Competing interests}

The authors declare that they have no competing interests.

\section{References}

1. Yoshimura N, Kinoshita H, Oka H, Muraki S, Mabuchi A, Kawaguchi $\mathrm{H}$ and Nakamura $\mathrm{K}$ : Cumulative incidence and changes in the prevalence of vertebral fractures in a rural Japanese community: A 10-year follow-up of the Miyama cohort. Arch Osteoporos 1: 43-49, 2006

2. Yoshimura N, Muraki S, Oka H, Mabuchi A, En-Yo Y, Yoshida M, Saika A, Yoshida H, Suzuki T, Yamamoto S, et al: Prevalence of knee osteoarthritis, lumbar spondylosis, and osteoporosis in Japanese men and women: The research on osteoarthritis/osteoporosis against disability study. J Bone Miner Metab 27: 620-628, 2009.

3. Kitazawa A, Kushida K, Yamazaki K and Inoue T: Prevalence of vertebral fractures in a population-based sample in Japan. J Bone Miner Metab 19: 115-118, 2001.

4. Wasnich RD: Vertebral fracture epidemiology. Bone 18 (3 Suppl): 179S-183S, 1996

5. Ismail AA, Cooper C, Felsenberg D, Varlow J, Kanis JA, Silman AJ and O'Neill TW: Number and type of vertebral deformities: Epidemiological characteristics and relation to back pain and height loss. European vertebral osteoporosis study group. Osteoporos Int 9: 206-213, 1999.

6. Panjabi MM: Physical properties and functional biomechanics of the spine. In: Clinical Biomechanics of the Spine. Panjabi MM and White AA (eds). LWW Corp., Philadelphia, PA, pp1-76, 1990.

7. Lindsay R, Silverman SL, Cooper C, Hanley DA, Barton I, Broy SB, Licata A, Benhamou L, Geusens P, Flowers K, et al: Risk of new vertebral fracture in the year following a fracture. JAMA 285: 320-323, 2001.

8. Hsu CC, Chao CK, Wang JL, Hou SM, Tsai YT and Lin J: Increase of pullout strength of spinal pedicle screws with conical core: Biomechanical tests and finite element analyses. J Orthop Res 23: 788-794, 2005.

9. Kilinçer C, Inceoglu S, Sohn MJ, Ferrara LA and Benzel EC: Effects of angle and laminectomy on triangulated pedicle screws. J Clin Neurosci 14: 1186-1191, 2007.

10. Hashemi A, Bednar D and Ziada S: Pullout strength of pedicle screws augmented with particulate calcium phosphate: An experimental study. Spine J 9: 404-410, 2009.

11. Sairyo K, Goel VK, Masuda A, Vishnubhotla S, Faizan A, Biyani A, Ebraheim N, Yonekura D, Murakami R and Terai T: Three-dimensional finite element analysis of the pediatric lumbar spine. Part I: pathomechanism of apophyseal bony ring fracture. Eur Spine J 15: 923-929, 2006.

12. Sairyo K, Goel VK, Masuda A, Vishnubhotla S, Faizan A, Biyani A, Ebraheim N, Yonekura D, Murakami R and Terai T: Three dimensional finite element analysis of the pediatric lumbar spine. Part II: Biomechanical change as the initiating factor for pediatric isthmic spondylolisthesis at the growth plate. Eur Spine J 15: 930-935, 2006.

13. Wells GA, Cranney A, Peterson J, Boucher M, Shea B, Robinson V, Coyle D and Tugwell P: Etidronate for the primary and secondary prevention of osteoporotic fractures in postmenopausal women. Cochrane Database Syst Rev 23: CD003376, 2008.

14. Wells GA, Cranney A, Peterson J, Boucher M, Shea B, Robinson V, Coyle D and Tugwell P: Alendronate for the primary and secondary prevention of osteoporotic fractures in postmenopausal women. Cochrane Database Syst Rev 23: CD001155, 2008.

15. Matsumoto T, Hagino H, Shiraki M, Fukunaga M, Nakano T, Takaoka K, Morii H, Ohashi Y and Nakamura T: Effect of daily oral minodronate on vertebral fractures in Japanese postmenopausal women with established osteoporosis: A randomized placebo-controlled double-blind study. Osteoporos Int 20: 1429-1437, 2009.

16. Wells G, Cranney A, Peterson J, Boucher M, Shea B, Robinson V, Coyle D and Tugwell P: Risedronate for the primary and secondary prevention of osteoporotic fractures in postmenopausal women. Cochrane Database Syst Rev 23: CD004523, 2008.

17. Chesnut CH III, Skag A, Christiansen C, Recker R, Stakkestad JA, Hoiseth A, Felsenberg D, Huss H, Gilbride J, Schimmer RC, et al: Effects of oral ibandronate administered daily or intermittently on fracture risk in postmenopausal osteoporosis. J Bone Miner Res 19: 1241-1249, 2004. 
18. Neer RM, Arnaud CD, Zanchetta JR, Prince R, Gaich GA, Reginster JY, Hodsman AB, Eriksen EF, Ish-Shalom S, Genant HK, et al: Effect of parathyroid hormone (1-34) on fractures and bone mineral density in postmenopausal women with osteoporosis. N Engl J Med 344: 1434-1441, 2001.

19. Nakamura T, Sugimoto T, Nakano T, Kishimoto $H$, Ito $M$, Fukunaga M, Hagino H, Sone T, Yoshikawa H, Nishizawa Y, et al: Randomized Teriparatide [human parathyroid hormone (PTH) 1-34] once-weekly efficacy research (TOWER) trial for examining the reduction in new vertebral fractures in subjects with primary osteoporosis and high fracture risk. J Clin Endocrinol Metab 97: 3097-3106, 2012.

20. Cummings SR, San Martin J, McClung MR, Siris ES, Eastell R, Reid IR, Delmas P, Zoog HB, Austin M, Wang A, et al: Denosumab for prevention of fractures in postmenopausal women with osteoporosis. N Engl J Med 361: 756-765, 2009.

21. Andrei D, Popa I, Brad S, Iancu A, Oprea M, Vasilian C and Poenaru DV: The variability of vertebral body volume and pain associated with osteoporotic vertebral fractures: Conservative treatment versus percutaneous transpedicular vertebroplasty. Int Orthop 41: 963-968, 2017.

22. Kanchiku T, Imajo Y, Suzuki H, Yoshida Y, Nishida N, Funaba M and Taguchi T: Operative methods for delayed paralysis after osteoporotic vertebral fracture. J Orthop Surg (Hong Kong) 25: 1-7, 2017

23. Gelb DE, Lenke LG, Bridwell KH, Blanke K and McEnery KW: An analysis of sagittal spinal alignment in 100 asymptomatic middle and older aged volunteers. Spine (Phila Pa 1976) 20: $1351-1358,1995$

24. Xie F, Zhou H, Zhao W and Huang L: A comparative study on the mechanical behavior of intervertebral disc using hyperelastic finite element model. Technol Health Care 25: 177-187, 2017.

25. Gertzbein SD: Scoliosis research society. Multicenter spine fracture study. Spine (Phila Pa 1976) 17: 528-540, 1992.

26. Jackson RP and Hales C: Congruent spinopelvic alignment on standing lateral radiographs of adult volunteers. Spine (Phila Pa 1976) 25: 2808-2815, 2000.

27. Glassman SD, Berven S, Bridwell K, Horton W and Dimar JR: Correlation of radiographic parameters and clinical symptoms in adult scoliosis. Spine (Phila Pa 1976) 30: 682-688, 2005.

28. Glassman SD, Bridwell K, Dimar JR, Horton W, Berven S and Schwab F: The impact of positive sagittal balance in adult spinal deformity. Spine (Phila Pa 1976) 30: 2024-2029, 2005.
29. Miyakoshi N, Kasukawa Y, Sasaki H, Kamo K and Shimada Y: Impact of spinal kyphosis on gastroesophageal reflux disease symptoms in patients with osteoporosis. Osteoporos Int 20: $1193-1198,2009$

30. Takahashi T, Ishida K, Hirose D, Nagano Y, Okumiya K, Nishinaga M, Matsubayashi K, Doi Y, Tani T and Yamamoto H: Trunk deformity is associated with a reduction in outdoor activities of daily living and life satisfaction in community-dwelling older people. Osteoporos Int 16: 273-279, 2005.

31. Wardlaw D, Van Meirhaeghe J, Ranstam J, Bastian L and Boonen S: Balloon kyphoplasty in patients with osteoporotic vertebral compression fractures. Expert Rev Med Devices 9: 423-436, 2012

32. Imai K, Ohnishi I, Bessho M and Nakamura K: Nonlinear finite element model predicts vertebral bone strength and fracture site. Spine (Phila Pa 1976) 31: 1789-1794, 2006.

33. Tawara D, Sakamoto J, Murakami H, Kawahara N, Oda J and Tomita K: Mechanical evaluation by patient-specific finite element analyses demonstrates therapeutic effects for osteoporotic vertebrae. J Mech Behav Biomed Mater 3: 31-40, 2010.

34. Tawara D, Sakamoto J, Murakami H, Kawahara N, Oda J and Tomita K: Mechanical therapeutic effects in osteoporotic L1-vertebrae evaluated by nonlinear patient-specific finite element analysis. JBSE 5: 499-514, 2010.

35. Tawara D, Sakamoto J, Murakami H, Kawahara N and Tomita K: Patient-specific finite element analyses detect significant mechanical therapeutic effects on osteoporotic vertebrae during a three-year treatment. JBSE 6: 248-261, 2011.

36. Itoi E, Sakurai M, Mizunashi K, Sato K and Kasama F: Long-term observations of vertebral fractures in spinal osteoporotics. Calcif Tissue Int 47: 202-208, 1990.

37. Iyer S, Lenke LG, Nemani VM, Albert TJ, Sides BA, Metz LN, Cunningham ME and Kim HJ: Variations in sagittal alignment parameters based on age: A prospective study of asymptomatic volunteers using full-body radiographs. Spine (Phila Pa 1976) 41: 1826-1836, 2016.

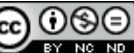

This work is licensed under a Creative Commons Attribution-NonCommercial-NoDerivatives 4.0 International (CC BY-NC-ND 4.0) License. 